\title{
Carpinus betulus a występowanie dziupli naturalnych w lasach gospodarczych
}

\author{
ŁUKASZ PIECHNIK
}

\begin{abstract}
PIEChNIK, Ł. 2020. Carpinus betulus and occurrence of natural tree hollows in managed forests. Fragmenta Floristica et Geobotanica Polonica 27(1): 33-43. Kraków. e-ISSN 2449-8890, ISSN 1640-629X.
\end{abstract}

\begin{abstract}
Tree-related microhabitats (e.g. necroses, tree hollows, dead branches) are an important factor affecting biodiversity in forest ecosystems. Among tree-related microhabitats, natural tree hollows are important for many organisms such as birds, small mammals, invertebrates and plants. The aim of the study was to determine what species of trees are associated with natural tree hollows and necroses. In 900 plots ( 0.05 ha each) located in 100 forest divisions of the Niepołomice Forest, natural tree hollows and necroses were recorded for the most numerous tree groups (pine, oak, lime, alder, hornbeam). Of all the studied tree species, the only species significantly positively associated with natural tree hollows and necrosis was Carpinus betulus. Pinus sylvestris was associated negatively with the occurrence of natural tree hollows. These results signal the very important role of hornbeam in increasing the richness of tree-related microhabitats in managed forests, and point to the need to promote hornbeam as an admixture tree species in managed forests. During forest work it is also important to ensure that a certain number of hornbeams reach old age; it will increase the number of natural tree hollows and consequently biodiversity in managed forest.
\end{abstract}

KEY WORDS: Carpinus betulus, managed forests, natural tree hollows, necrosis, tree-related microhabitats

Ł. Piechnik, Instytut Botaniki im. W. Szafera Polskiej Akademii Nauk, ul. Lubicz 46, 31-512 Kraków, Polska; e-mail: l.piechnik@botany.pl

\begin{abstract}
WSTĘP
Mikrosiedliska są niewielkimi fragmentami środowiska stanowiącymi najbliższe otoczenie organizmu i bezpośrednio na niego oddziałującymi, często odnoszącymi się do konkretnych struktur roślinności lub rodzajów gleby (FULLER 2012). W ekosystemach leśnych występują specyficzne, nadrzewne mikrosiedliska, np. dziuple, próchnowiska, pęknięcia kory, martwe konary itp. (GROSSMANN i in. 2018; KozÁK i in. 2018; LARRIEU i in. 2018). Mają one istotne znaczenie dla różnorodności biologicznej, gdyż wiele gatunków roślin, grzybów i zwierząt potrzebuje ich jako miejsc niezbędnych do swego rozwoju (REGNERY i in. 2013; BERNES i in. 2016).

Dla wielu grup organizmów bardzo ważnym nadrzewnym mikrosiedliskiem są dziuple naturalne (MAZIARZ \& BROUGHTON 2015; WESOŁOWSKI i in. 2018), które w odróżnieniu
\end{abstract}


od dziupli wykutych przez ptaki, powstają najczęściej na skutek procesów inicjowanych przez uszkodzenia mechaniczne lub działalność grzybów (RANIUs i in. 2009). Dziuple naturalne są cennymi mikrosiedliskami zapewniającymi podłoże do wzrostu dla epifitycznych porostów, mszaków i roślin naczyniowych (SZYMCZYK \& ZALEWSKA 2008) oraz dostarczającymi bazy żerowej, schronienia lub miejsc lęgowych dla dużej liczby zwierząt (CZESZCZEWIK \& WALANKIEWICZ 2003). Są one miejscem rozwoju dla wielu bezkręgowców, w tym chrząszczy saproksylicznych (RAnius \& NiLSSON 1997; Gouix i in. 2015) i zaleszczotków (Christophoryová i in. 2017). Stanowią one również ważne mikrosiedlisko dla dziuplaków wtórnych czyli ptaków, które choć lęgną się w dziuplach, to same bezpośrednio ich nie tworzą. Do typowych dziuplaków wtórnych w lasach strefy umiarkowanej w Europie zaliczane są m.in. sikory (Paridae), muchołówki (Ficedula spp.), pełzacze (Certhia spp.), kowalik (Sitta europaea), szpak zwyczajny (Sturnus vulgaris), krętogłów (Jynx torquilla) czy sowy (Strigiformes) (MAZIARZ \& BROUGHTON 2015; WesOŁOWSKI i in. 2018). W dziuplach naturalnych schronienie znajdują także ssaki. Dostępność tych mikrosiedlisk jest limitująca dla nietoperzy z rodzajów borowiec (Nyctalus spp.), karlik (Pipistrellus spp.), nocek (Myotis spp.) i mroczek (Eptesicus spp.) (RACEY \& ENTwistLE 2003; REgnery i in. 2013). Dziuple są też miejscem dziennego odpoczynku i rozrodu dla licznych gatunków gryzoni, m.in. wiewiórki rudej (Sciurus vulgaris), polatuchy syberyjskiej (Pteromys volans), popielicowatych (Gliridae) czy myszarek (Apodemus spp.) oraz małych ssaków drapieżnych (Carnivora) (JĘDRZEJEWSKI i in. 1992; BIRKS i in. 2005; JURCZYSZYN 2007; SUZUKI i in. 2013).

Występowanie dziupli naturalnych w ekosystemie leśnym może być związane z elementami struktury lasu takimi jak: skład gatunkowy, wiek czy grubość drzew (WINTER \& MöLLER 2008). Obecność dziupli naturalnych w lesie zależy między innymi od ilości martwic na pniach i konarach drzew. Martwice powstają zwykle na skutek uderzeń przewracających się drzew o drzewa stojące (TAVANKAR i in. 2013). Martwice są mikrosiedliskami, które bezpośrednio nie mają dużego znaczenia, zwłaszcza dla kręgowców, ale mogą być pierwszym etapem powstawania kolejnych mikrosiedlisk, w tym głównie dziupli. Do tej pory przeprowadzono niewiele badań zależności pomiędzy występowaniem dziupli naturalnych i martwic a cechami drzewostanów (WinTER \& MöLler 2008; VuIDOT i in. 2011; JoHANN \& SCHAICH 2016). Brak również badań wykazujących wpływ konkretnych gatunków drzew leśnych na występowanie tych nadrzewnych mikrosiedlisk w ekosystemach leśnych strefy umiarkowanej (VUIDOT i in. 2011). Tymczasem niektóre gatunki drzew mogą być podatne na powstawanie na nich dziupli naturalnych. Do takich gatunków należy Carpinus betulus L. (grab zwyczajny).

Grab posiada specyficzną budowę pnia, charakteryzującą się skrętem włókien, co skutkuje tym, że w przekroju poprzecznym przybiera on kształt nieregularny z licznymi zagłębieniami (Ryc. 1). U gatunku tego często występują też zakorki, czyli wrośnięte w drewno płaty kory (ŚLEZZAK 2010). Pnie starszych drzew posiadają korę o zróżnicowanej grubości z licznymi płytkimi spękaniami, co zwiększa prawdopodobieństwo miejscowego odpadania kory i powstawania martwic bocznych (RICHTER 2015). Budowa ta sprzyja występowaniu mikrosiedlisk nadrzewnych. Nawet młodsze osobniki grabu, w odróżnieniu od np. młodych buków, wykształcają niewielkie zagłębienia na pniach, co może inicjować powstawanie 


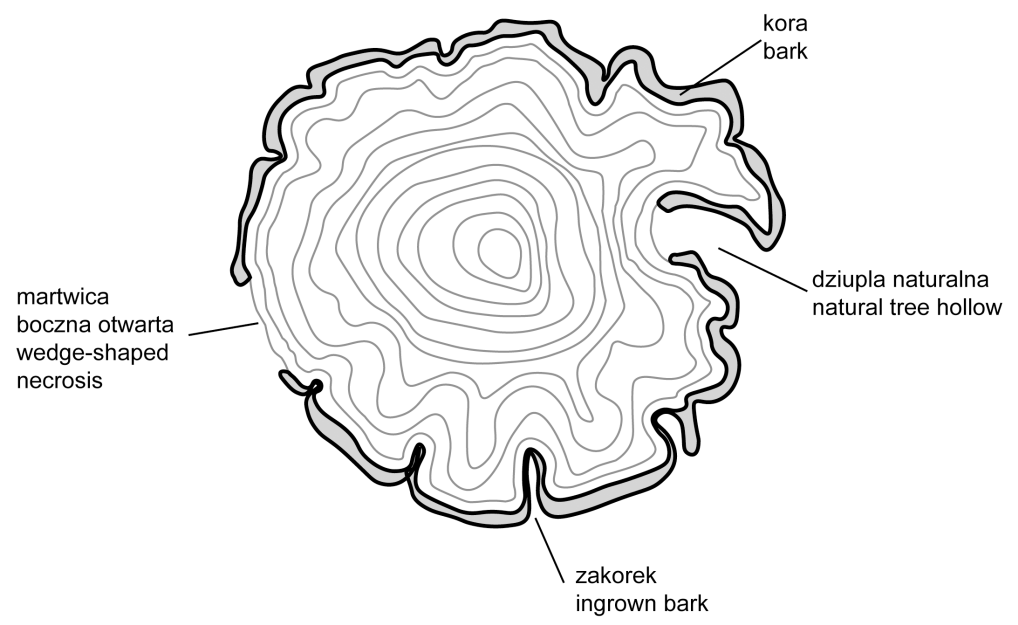

Ryc. 1. Schemat przekroju poprzecznego pnia Carpinus betulus

Fig. 1. Cross section of trunk Carpinus betulus

w tych miejscach dziupli naturalnych (SURMIŃSKI 1993). Na podstawie tych przesłanek, w niniejszych badaniach testowano hipotezę, że dziuple naturalne i martwice częściej występują na grabie zwyczajnym niż na innych gatunkach drzew występujących w lasach gospodarczych.

\section{METODY}

\section{Teren badań}

Badania przeprowadzono w Puszczy Niepołomickiej (50² $\left.02^{\prime} \mathrm{N}, 20^{\circ} 33^{\prime} \mathrm{E}\right)$, dużym (ok. 10600 ha), nizinnym kompleksie leśnym, rozciągającym się w zachodniej części Kotliny Sandomierskiej, w widłach rzek Wisły i Raby. Wysokości bezwzględne na tym obszarze wynoszą od 180 do 210 m n.p.m. (KONDRACKI 2002). W składzie gatunkowym drzewostanów dominuje Pinus silvestris, Quercus robur i Q. petraea oraz Alnus glutinosa. Mniejszy udział stanowią takie gatunki jak Fagus sylvatica, Betula pendula, Larix decidua i Carpinus betulus. Udział tego ostatniego w powierzchni leśnej Puszczy Niepołomickiej wzrasta w ostatnich latach (PUL 2011). W Puszczy Niepołomickiej dominują dwa zbiorowiska roślinne: Pino-Quercetum (74\%) oraz Tilio-Carpinetum (22\%). Większość powierzchni (98,5\%) Puszczy Niepołomickiej stanowi las gospodarczy, w którym stosuje się rębnie zupełne gniazdowe z odnowieniem sztucznym (PUL 2011). Pozostała, niewielka część powierzchni została objęta ochroną rezerwatową. Na terenie Puszczy Niepołomickiej wyznaczono kilka obszarów Natura 2000: Obszar Specjalnej Ochrony Puszcza Niepołomicka (PLB120002), czyli tzw. obszar ptasi oraz trzy Specjalne Obszary Ochrony: Torfowisko Wielkie Błoto (PLH120080), Koło Grobli (PLH120008) oraz Lipówka (PLH120010), czyli tzw. obszary siedliskowe.

\section{Pomiar drzewostanu i nadrzewnych mikrosiedlisk}

Badania przeprowadzono na 100 dziesięciohektarowych $(316 \times 316 \mathrm{~m})$ powierzchniach badawczych. $\mathrm{Na}$ każdej powierzchni badawczej regularnie rozmieszczono 9 prostokątnych $(20 \times 25 \mathrm{~m})$ poletek pomiarowych. Na poletkach odnotowywano gatunek drzewa oraz, posługując się lornetką, występowanie dziupli 
naturalnych i martwic. Pomiarami objęto wszystkie drzewa grubsze niż $30 \mathrm{~cm}$ w pierśnicy, następujących gatunków: Pinus sylvestris, Quercus robur, Q. petraea, Tilia cordata, T. platyphyllos, Alnus glutinosa, A. incana oraz Carpinus betulus. W analizach gatunki blisko spokrewnione traktowano jako jeden takson, a nazwy gatunkowe skracano do nazw rodzajowych (sosna, dąb, lipa, olsza, grab).

\section{Analiza danych}

Do zbadania związku pomiędzy występowaniem mikrosiedlisk nadrzewnych (dziupli naturalnych i martwic) a gatunkiem drzewa użyto testu chi-kwadrat. Każdy gatunek drzewa został scharakteryzowany za pomocą dwóch wielkości: liczby osobników (o pierśnicy $>30 \mathrm{~cm}$ ) ze stwierdzoną obecnością danego mikrosiedliska oraz liczby osobników bez tego mikrosiedliska. W teście nie uwzględniono sosny zwyczajnej, na której dziuple naturalne występują jedynie sporadycznie i tylko na starych drzewach, których jest niewiele na terenie Puszczy Niepołomickiej (BORATYŃSKI 1993; ZAWADZKA i in. 2016). Równocześnie jest ona gatunkiem dominującym w Puszczy Niepołomickiej i jej uwzględnienie w teście mogłoby zniekształcić ocenę wpływu gatunków liściastych.

W celu zbadania związku pomiędzy występowaniem mikrosiedlisk nadrzewnych (dziupli naturalnych i martwic) a średnicą grubych grabów, podzielono drzewa tego gatunku na trzy klasy grubości $(31-40 \mathrm{~cm}$, $41-50 \mathrm{~cm}$ i powyżej $50 \mathrm{~cm}$ ). Do zbadania tego związku użyto testu chi-kwadrat, w którym każda z trzech klas grubości grabów była scharakteryzowana dwoma wielkościami: liczbą osobników danej klasy grubości ze stwierdzoną obecnością mikrosiedliska oraz liczbą osobników danej klasy grubości bez tego mikrosiedliska. Analizy przeprowadzono w środowisku R (R CoRE TEAm 2019).

\section{WYNIKI}

Na powierzchniach badawczych odnotowano łącznie 7649 drzew grubszych niż $30 \mathrm{~cm}$ w pierśnicy, w tym 1836 dębów, 414 grabów, 403 lipy, 382 olsze i 4614 sosen. Na 128 drzewach stwierdzono występowanie dziupli naturalnych, a na 726 drzewach występowanie martwic. Test chi-kwadrat wykazał, że w drzewostanach gospodarczych Puszczy Niepołomickiej obecność dziupli naturalnych $\left(\chi^{2}=71,34 ; p<0,0001\right)$ i martwic $\left(\chi^{2}=43,51\right.$; $p<0,0001$ ) jest silnie zależna od gatunku drzewa (Ryc. 2). Według analizy reszt standaryzowanych testu chi-kwadrat, gatunkiem mającym największy wpływ na ten wynik był grab (dla grabu odnotowano największe różnice pomiędzy wartościami oczekiwanymi a uzyskanymi w badaniach); jego związek z tymi mikrosiedliskami był dodatni, a pozostałych
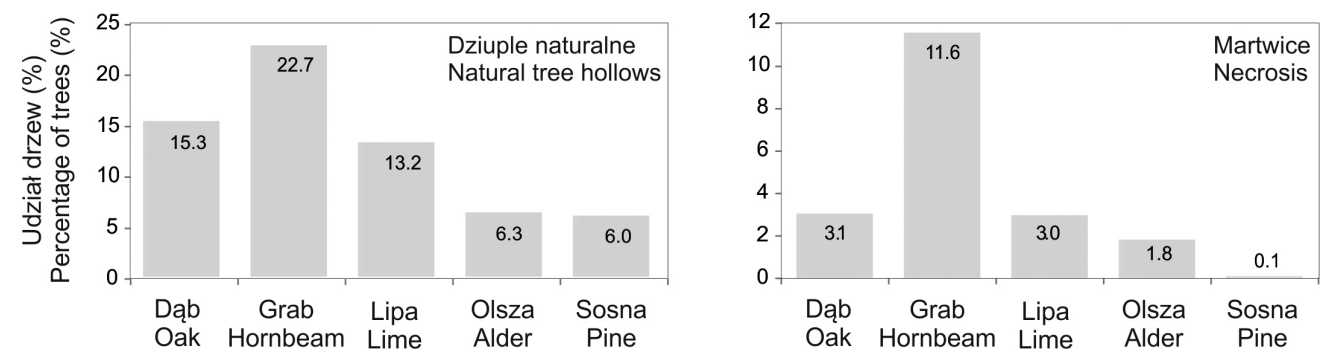

Ryc. 2. Udział procentowy drzew posiadających dziuple naturalne i martwice

Fig. 2. Percentage of trees with natural tree hollows and necrosis 

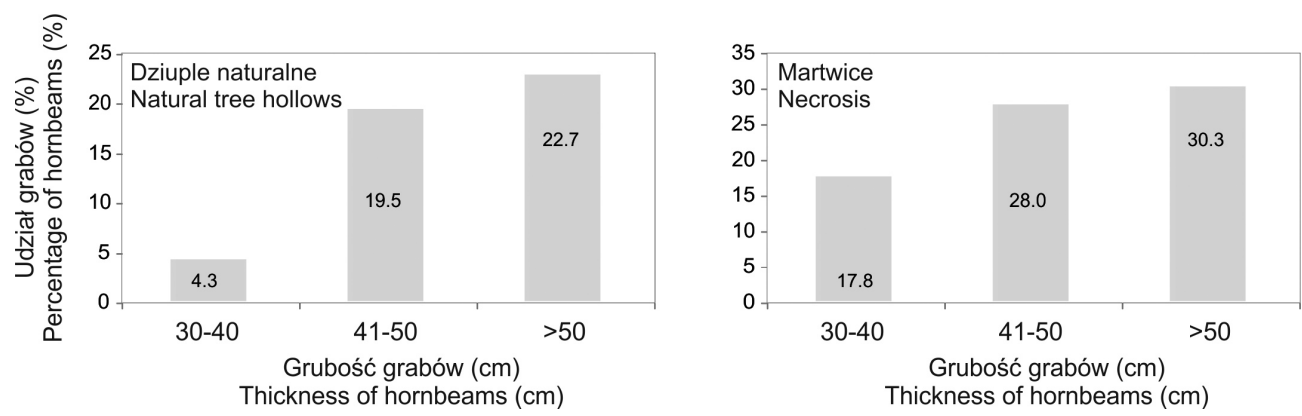

Ryc. 3. Udział procentowy grabów posiadających dziuple naturalne i martwice w klasach grubości

Fig. 3. Percentage of hornbeams with natural tree hollows and necrosis in thickness classes

gatunków - ujemny. Różnice pomiędzy dębem, lipą i olszą we frekwencji osobników z mikrosiedliskami były znikome.

Zarówno obecność dziupli naturalnych $\left(\chi^{2}=26,94 ; p<0,0001\right)$ jak i martwic $\left(\chi^{2}=7,15\right.$; $p<0,05$ ) była zależna od grubości grabów (Ryc. 3). Według analizy reszt standaryzowanych testu chi-kwadrat, związek grabów o grubości poniżej $40 \mathrm{~cm}$ zarówno z dziuplami naturalnymi jak i martwicami był ujemny, a w przypadku drzew o grubości powyżej $40 \mathrm{~cm}$ - dodatni. Różnice we frekwencji grabów z badanymi mikrosiedliskami nadrzewnymi pomiędzy drzewami o grubości od 41 do $50 \mathrm{~cm}$ a tymi powyżej $50 \mathrm{~cm}$ były niewielkie.

\section{DYSKUSJA}

Wyniki badań przeprowadzonych w lesie gospodarczym pokazują, że grab zwyczajny jest gatunkiem drzewa, na którym dziuple naturalne i martwice występują częściej niż na innych współwystępujących drzewach, takich jak sosny, dęby, lipy czy olsze. Przyczyną jest prawdopodobnie naturalna budowa pnia tego gatunku, charakteryzująca się występowaniem krzywizn, zagłębień, skrętu włókien i zakorków oraz stosunkowo cienką korą. Ta ostatnia z wymienionych cech budowy sprzyja tworzeniu się zgorzeliny (oparzeliny) kory, czyli nieodwracalnemu uszkodzeniu miazgi na skutek wysokich temperatur, np. w wyniku silnego nasłonecznienia fragmentu pnia. W miejscu dotkniętym zgorzeliną, kora pęka i z czasem odpada, co sprzyja tworzeniu się martwic bocznych (SURMIŃSKI 1993; ŚLĘZAK 2010). Zarówno w lasach chronionych jak i gospodarczych, przewracające się drzewa często powodują rozległe otarcia kory drzew stojących. Najłatwiej takie uszkodzenia powstają właśnie u drzew posiadających stosunkowo cienką korę. W lesie gospodarczym dodatkowym czynnikiem zwiększającym prawdopodobieństwo wystąpienia takich uszkodzeń, a w ich konsekwencji martwic, są prace związane ze ścinką oraz zrywką drzew (VASILIAUSKAS 2001). Nawet lekkie otarcie spadającego drzewa o pień stojącego grabu powoduje przerwanie kory i uszkodzenie drewna, co w przypadku np. dębu (gatunku o znacznie grubszej korze) wymagałoby mocniejszego uderzenia (TAVANKAR i in. 2013). Martwice będące uszkodzeniami kory, łyka i drewna są zasiedlane głównie przez grzyby i owady (LIMBECK-LILIENAU 2003; ZÚBRIK i in. 2013). Działalność tych organizmów skutkuje z czasem powstawaniem 
w miejscu martwicy dziupli naturalnych i próchnowisk. Cechą grabu jest także posiadanie łatwo obłamujących się gałęzi np. pod wpływem okiści śnieżnej (FALIŃSKI \& PAwLACZYK 1993). Dodatkowo, u starych okazów tego gatunku częste jest powstawanie pęknięć wzdłuż pni i konarów. W tych uszkodzonych miejscach drewno próchnieje, co również sprzyja powstawaniu dziupli naturalnych (WeSOŁOWSKI \& ToMiAŁOJĆ 1986; WALANKIEWICZ \& CZESZCZEwIK 2006). Potwierdza to wykazana pozytywna relacja pomiędzy występowaniem dziupli naturalnych i martwic a średnicą grabów. Częste występowanie dziupli na grabach ma prawdopodobnie znaczenie dla wzrostu bioróżnorodności w ekosystemie leśnym. Świadczą o tym badania przeprowadzone w Puszczy Białowieskiej. Wykazano, że grab jest gatunkiem, na którym najczęściej swe gniazda zakłada muchołówka żałobna Ficedula hypoleuca (CZESZCZEWIK \& WALANKIEWICZ 2003) oraz muchołówka białoszyja F. albicollis (WALANKIEWICZ \& CZESZCZEWIK 2006). Inne, niekiedy licznie występujące gatunki drzew, np. lipy czy wiązy (Ulmus spp.) są rzadziej użytkowane jako miejsca lęgowe (WesoŁowski 1989; CZESZCZewiK \& WaLANKIEwicZ 2003; KrYštufeK 2010).

Grab zwyczajny jest dominującym gatunkiem drzewa w grądach środkowoeuropejskich Carpinion betuli i w nich znajduje swe optimum siedliskowe, ale występuje również w lasach mieszanych, borach mieszanych, lasach wyżynnych, a nawet w łęgach (FALIŃSKI \& PAWLACZYK 1993). Prawdopodobnie gatunek ten stanowił w przeszłości większy udział w składach gatunkowych drzewostanów dziś użytkowanych jako gospodarcze (RALSKA-JASIEWICZOWA 1964; CzURAJ 1982). Grab jest drzewem dobrze tolerującym zgryzanie przez ssaki roślinożerne i wykazuje dużą zdolność wytwarzania odrośli z pozostawionego po ścince pnia, co wraz $\mathrm{z}$ obfita produkcja nasion predysponuje go do dominacji w składach gatunkowych grądów (FALIŃSKI \& PAWLACZYK 1993). Mimo wysokiej wartości opałowej i bardzo dobrych parametrów technicznych takich jak duża twardość i wysoka odporność na ściskanie (SURMIŃSKI 1993), grab nie był do tej pory promowany na szerszą skalę w lasach gospodarczych, a jedynie na siedliskach grądowych stanowił większy udział w drzewostanach (FALIŃSKI \& PAWLACZYK 1993). Powodem tego była prawdopodobnie tendencja do częstego występowania licznych wad drewna grabowego, m.in. krzywizn, skrętu włókien, zakorków, martwic oraz próchnowisk. Gatunek ten nie znalazł szerszego zastosowania w przemyśle drzewnym, a w konsekwencji nie był hodowany w lasach gospodarczych na skalę, na jaką pozwalałyby warunki siedliskowe (ŚRODOŃ 1993). Od lat 90. XX w. zauważalny jest stopniowy, powolny powrót do uwzględniania graba w składach gatunkowych upraw leśnych i promowania jego odnowień naturalnych. Szeroka amplituda ekologiczna tego gatunku powoduje, że grab może być sadzony również na siedliskach, na których stanowi tylko domieszkę w drzewostanie (ZASADY HoDOwLi LASU 2012; RocZNIK STATYSTYCZNY LEŚNICTWA 2018). Coraz większe jest zapotrzebowanie na dobrej jakości drewno opałowe, a w przypadku drewna grabu jego wartość opałowa porównywana jest do drewna buka, uznawanego za jedno z najbardziej kalorycznych. Drewno grabowe nie wymaga tak długiego okresu sezonowania jak buk, posiada też od niego wyższą gęstość i mniejszą wilgotność (SURMiŃSKI 1993). W ostatnich latach udział grabu w lasach Polski wzrasta (RocZnik STATYSTYCZnY Leśnictwa 2018). Możemy się zatem spodziewać, że zwiększy się w konsekwencji liczebność mikrosiedlisk związanych z grabem, w tym m.in. dziupli naturalnych i martwic. 
Cechy, które zwiększają wartość grabu dla podnoszenia bioróżnorodności w ekosystemie leśnym są równocześnie cechami zaniżającymi wartość gospodarczą drewna tego gatunku. W lasach gospodarczych graby posiadające rozległe martwice są dla zarządcy lasu miejscem potencjalnej infekcji patogenów i w konsekwencji deprecjacji surowca drzewnego. W związku z tym drzewa z martwicami na pniu są wyznaczane do usunięcia podczas trzebieży i cięć sanitarnych. Badania prowadzone w lasach Europy potwierdzają, że mikrosiedliska związane z drzewami starymi i zamierającymi są mniej liczne w lasach intensywnie zagospodarowanych (MüLlER \& BüTLER 2010; PAWLACZYK 2014; ANDERSSON i in. 2017). $\mathrm{Z}$ drugiej strony, gospodarka leśna stwarza nowe mikrosiedliska związane z drzewami. Obok pniaków, stert gałęzi i pozostałości pozrębowych to właśnie martwice i uszkodzenia mechaniczne na pniach są strukturami, których powstawanie wiąże się z gospodarczym wykorzystaniem lasów. Aby jednak mikrosiedliska te mogły mieć większe znaczenie dla szerszej grupy organizmów, należałoby pozwolić pewnej liczbie martwic przekształcić się w dziuple naturalne lub próchnowiska.

Intensywna gospodarka leśna prowadzona w Polsce przez cały XIX w. i większość XX w. promowała wybrane gatunki drzew, takie jak np. sosna, świerk, dąb czy olsza czarna, marginalizując inne, np. klon zwyczajny, lipy, wiązy, osikę czy graba (BRODA 2000). Miało to wpływ na występowanie w lasach mikrosiedlisk związanych z konkretnymi gatunkami drzew. Sosna zwyczajna rosnąca w drzewostanie jest zwykle drzewem o prostym pniu, małej liczbie gałęzi i wysoko osadzonej koronie. Mała liczba konarów i gałęzi, a w konsekwencji mała liczba miejsc po ich złamaniach w połączeniu z grubą korą dolnych części pni powoduje, że na sosnach dziuple naturalne powstają sporadycznie i głównie na starych drzewach (ZAWADZKA $\mathrm{i}$ in. 2016).

W celu zwiększenia bioróżnorodności w lasach gospodarczych należałoby kontynuować obecną tendencję do zwiększania udziału tego gatunku w drzewostanach. Do wniosku tego prowadzą uzyskane wyniki, wskazujące na dużą rolę grabu w tworzeniu się dziupli naturalnych i martwic w drzewostanie gospodarczym. Samo promowanie grabu zwyczajnego w składach gatunkowych odnowień jednak nie wystarczy, aby zwiększyć ilość nadrzewnych mikrosiedlisk z nim związanych. W ramach zaleceń dotyczących ochrony różnorodności biologicznej w praktyce leśnej i odnoszących się do pozostawiania w lesie tzw. drzew biocenotycznych (INSTRUKCJA OCHRONY LASU 2012), należy rozważyć konieczność pozostawiania starych grabów w lasach gospodarczych. Drzewa te wraz z towarzyszącymi im nadrzewnymi mikrosiedliskami podniosłyby bioróżnorodność lasów i pozwoliłyby na przetrwanie zagrożonych gatunków.

Podziękowania. Badania były finansowane z środków Państwowego Gospodarstwa Leśnego Lasy Państwowe w ramach grantu pt. Ksztattowanie się zasobów martwego drewna $w$ siedliskach przyrodniczych $w$ warunkach prowadzenia zrównoważonej gospodarki leśnej ( $\mathrm{Nr}$ OR.271.3.9.215) oraz środków statutowych Instytutu Botaniki im. W. Szafera Polskiej Akademii Nauk. Dziękuję Nadleśnictwu Niepołomice za umożliwienie prowadzenia badań na terenie Puszczy Niepołomickiej oraz wszystkim osobom, które brały udział w pracach terenowych. Pragnę podziękować dr hab. Magdalenie Żywiec, prof. dr. hab. Janowi Holeksie, dr. inż. Przemysławowi Kurkowi oraz dr. Mateuszowi Ledwoniowi za szereg cennych uwag do tekstu. Dwóm anonimowym recenzentom dziękuję za pomocne sugestie. 


\section{LITERATURA}

Andersson J., Gómez E. D., Michon S. \& Roberge J. M. 2017. Tree cavity densities and characteristics in managed and unmanaged Swedish boreal forest. - Scandinavian Journal of Forest Research 33: 233-244.

Bernes C., Jonsson B. G., Junninen K., Lohmus A., Macdonald E., Muller J. \& Sandstrom J. 2016. What are the impacts of dead-wood manipulation on the biodiversity of temperate and boreal forests? A systematic review protocol. s. 12. Mistra EviEM Protocol SR12, Sztokholm.

Birks J. D. S., Messenger J. E. \& Halliwell E. C. 2005. Diversity of den sites used by pine martens Martes martes: a response to the scarcity of arboreal cavities? - Mammal Review 35: 313-320.

BoRATYŃSKi A. 1993. Systematyka i geograficzne rozmieszczenie. Charakterystyka morfologiczna. - W: S. BiaŁoboK, A. BoratyŃski \& W. BugaŁa (red.), Biologia sosny zwyczajnej, s. 45-50. Sorus, Poznań - Kórnik.

BrodA J. 2000. Historia leśnictwa w Polsce. s. 368. Wydawnictwo Akademii Rolniczej im. Augusta Cieszkowskiego w Poznaniu, Poznań.

Christophoryová J., JajCAYová D. \& KrajČOvičová K. 2017. Pseudoscorpions (Arachnida: Pseudoscorpiones) living in tree microhabitats in Slovakia. - Klapalekiana 53: 283-297.

Czeszczewik D. \& Walankiewicz W. 2003. Natural nest sites of the Pied Flycatcher Ficedula hypoleuca in a primeval forest. - Ardea 91(2): 221-230.

Czuraj M. 1982. Skład gatunkowy drzewostanów w Polsce w latach 1918-1978. - Studia Ośrodka Dokumentacji Fizjograficznej PAN O/Kraków 10: 83-98.

Faliński J. B. \& PawlaczyK P. 1993. Zarys ekologii. - W: W. BugaŁa (red.), Grab zwyczajny Carpinus betulus L. Nasze drzewa leśne, s. 157-264. Sorus, Poznań - Kórnik.

Fuller R. J. 2012. Birds and habitat. Relationships in changing landscapes. s. 542. Cambridge University Press, Cambridge.

Gouix N., Sebek P., Valladares L., Brustel H. \& Brin A. 2015. Habitat requirements of the violet click beetle (Limoniscus violaceus), an endangered umbrella species of basal hollow trees. - Insect Conservation and Diversity 8: 418-427.

Grossmann J., Schultze J., Bauhus J. \& Pyttel P. 2018. Predictors of microhabitat frequency and diversity in mixed mountain forests in south-western Germany. - Forests 9(3): 104, doi:10.3390/f9030104.

InSTRUKCJA OChrony LASU. 2012. s. 124. Centrum Informacyjne Lasów Państwowych, Warszawa.

JędrzeJewski W., Jędrzejewska B. \& McNeish E. 1992. Hunting success of the weasel Mustela nivalis and escape tactics of forest rodents in Białowieża National Park. - Acta Theriologica 37: 319-328.

JohanN F. \& Schaich H. 2016. Land ownership affects diversity and abundance of tree microhabitats in deciduous temperate forests. - Forest Ecology and Management 380: 70-81.

JURCZYSZYN M. 2007. Hibernation cavities used by the edible dormouse, Glis glis (Gliridae, Rodentia). - Folia Zoologica 56(2): 162-168.

Kondracki J. 2002. Geografia regionalna Polski. s. 440. Wydawnictwa Naukowe PWN, Warszawa.

Kozák D., Mikoláš M., Svitok M., Bače R., Paillet Y., Larrieu L. \& Nagel T. A. 2018. Profile of tree-related microhabitats in European primary beech-dominated forests. - Forest Ecology and Management 429: 363-374.

KRYŠTUFEK B. 2010. Glis glis (Rodentia: Gliridae). - Mammalian Species 42: 195-206.

Larrieu L., Paillet Y., Winter S., Butler R., Kraus D., Krumm F., Lachat T., Michel A. K., Regnery B. \& VANDEKERKHOVE K. 2018. Tree related microhabitats in temperate and Mediterranean European forest: A hierarchical typology for inventory standardization. - Ecological Indicators 83: 194-207. 
LiMBECK-LILIENAU B. 2003. Residual stand damage caused by mechanized harvesting systems. - W: B. LiMBeck-Lilienau, Th. Steinmüller \& K. STAmpfer (red.), Proceedings of the Austro2003 meeting: High Tech Forest Operations for Mountainous Terrain. CD ROM. s. 11. October 5-9, Schlaegl, Austria. University of Natural Resources and Life Sciences, Wiedeń.

Maziarz M. \& Broughton R. K. 2015. Breeding microhabitat selection by Great Tits Parus major in a deciduous primeval forest (Białowieża National Park, Poland). - Bird Study 62: 358-367.

MÜLLER J. \& BÜTLER R. 2010. A review of habitat thresholds for dead wood: a baseline for management recommendations in European forests. - European Journal of Forest Research 129: 981-992.

PAWLACZYK P. 2014. Martwe drewno i mikrosiedliska nadrzewne w leśnych siedliskach przyrodniczych Puszczy Drawskiej. - Studia i Materiały Centrum Edukacji Przyrodniczo-Leśnej w Rogowie 16(41): 86-97.

PUL. 2011. Plan Urządzenia Lasu Nadleśnictwa Niepołomice na okres gospodarczy od 1 stycznia 2012 do 31 grudnia 2021. Biuro Urządzania Lasu i Geodezji Leśnej, Oddział w Krakowie.

R Core TeAm. 2019. R: A language and environment for statistical computing. R Foundation for Statistical Computing, Vienna, Austria. http://www.R-project.org/.

Racey P. A. \& Entwistle A. C. 2003. Conservation ecology of bats. - W: T. H. Kunz \& M. B. Fenton (red.), Bat ecology, s. 680-743. University of Chicago Press, Chicago.

Ralska-Jasiewiczowa M. 1964. Correlation between the Holocene history of the Carpinus betulus and prehistoric settlement in North Poland. - Acta Societatis Botanicorum Poloniae 33(2): 461-468.

Ranius T. \& NiLsson S. G. 1997. Habitat of Osmoderma eremita Scop. (Coleoptera: Scarabaeidae), a beetle living in hollow trees. - Journal of Insect Conservation 1: 193-204.

Ranius T., NikLasson M. \& Berg N. 2009. Development of tree hollows in pedunculate oak (Quercus robur). - Forest Ecology and Management 257: 303-310.

Regnery B., Couvet D., Kubarek L., Julien J. F. \& Kerbiriou C. 2013. Tree microhabitats as indicators of bird and bat communities in Mediterranean forests. - Ecological Indicators 34: 221-230.

RICHTER C. 2015. Wood characteristics: description, causes, prevention, impact on use and technological adaptation. s. 222. Springer, Cham.

RocZnik StatystycZny LeŚnictwa. 2018. s. 334. Główny Urząd Statystyczny, Warszawa.

SURMiŃsKi J. 1993. Właściwości techniczne i możliwości zastosowania drewna. - W: W. BugAŁA (red.), Grab zwyczajny Carpinus betulus L. Nasze drzewa leśne, s. 325-330. Sorus, Poznań - Kórnik.

Suzuki K., Sagawa M. \& Yanagawa H. 2013. Nest cavity selection by the Siberian flying squirrel Pteromys volans. - Hystrix 24: 187-189.

SZYMCZYK R. \& ZALEwSKA A. 2008. Lichen biota of the Grabianka river valley in the Elblag Upland (Wysoczyzna Elbląska). - Polish Journal of Natural Sciences 23(2): 398-414.

ŚLĘZAK G. 2010. Atlas wad drewna. s. 280. Powszechne Wydawnictwo Rolnicze i Leśne, Warszawa.

ŚRodoń A. 1993. Grab w historii lasów Polski. - W: W. BugaŁa (red.), Grab zwyczajny Carpinus betulus L. Nasze drzewa leśne, s. 7-16. Sorus, Poznań - Kórnik.

Tavankar F., Majnounian B. \& Bonyad A. 2013. Felling and skidding damage to residual trees following selection cutting in Caspian forests of Iran. - Journal of Forest Science 59(5): 196-203.

VASILIAUSKAS R. 2001. Damage to trees due to forestry operations and its pathological significance in temperate forests: a literature review. - Forestry 74(4): 319-336.

Vuidot A., PAillet Y., ArchauX F. \& Gosselin F. 2011. Influence of tree characteristics and forest management on tree microhabitats. - Biological Conservation 144: 441-450. 
Walankiewicz W. \& CzeszczewiK D. 2006. Znaczenie grabu zwyczajnego Carpinus betulus dla dziuplaków w Białowieskim Parku Narodowym. - Chrońmy Przyrodę Ojczystą 62: 50-57.

WesOŁOWSKI T. 1989. Nest-sites of hole-nesters in a primaeval forest (Białowieża National Park, Poland). - Acta Ornithologica 25: 321-351.

Wesolowski T. \& MARTIN K. 2018. Tree holes and hole nesting birds in European and North American forests. - W: G. Mikusiński, J. M. Roberge \& R. J. FulLeR (red.), Ecology and conservation of European forest birds, s. 79-134. Cambridge University Press, Cambridge.

WesoŁowsKi T. \& TomiaŁojć L. 1986. The breeding ecology of woodpeckers in a temperate primaeval forest - preliminary data. - Acta Ornithologica 22: 1-22.

Winter S. \& MöLLER G. C. 2008. Microhabitats in lowland beech forests as monitoring tool for nature conservation. - Forest Ecology and Management 255: 1251-1261.

Zasady Hodowli Lasu. s. 72. Centrum Informacyjne Lasów Państwowych, Warszawa.

ZawadzKa D., Drozdowski S., ZawADZKi G. \& ZawadZKi J. 2016. The availability of cavity trees along an age gradient in fresh pine forests. - Silva Fennica 50(3), id 1441.13p, http://dx.doi.org/10.14214/ sf.1441.

ZÚBRIK M., KunCA A. \& CsOKA G. 2013. Insects and diseases damaging trees and shrubs of Europe. s. 536. Napedition, Paryż.

\section{SUMMARY}

Tree-related microhabitats (necroses, natural tree hollows, dead branches) are important for forest biodiversity. Among them, natural tree hollows are valuable tree-related microhabitats for many groups of organisms. They provide sites for epiphytic lichens, bryophytes and vascular plants to grow. These structures also offer feeding, shelter or breeding grounds for a large number of animals, especially for secondary hole-nesting birds. The occurrence of natural tree hollows in the forest can be associated with the forest structure (e.g. tree species composition, age or thickness of trees). There have been few studies on the relationship between the occurrence of natural tree hollows and forest structure or on the effect of a particular tree species on the occurrence of natural tree hollows in temperate forest ecosystems. Some species of trees (e.g. European hornbeam Carpinus betulus; hereafter: hornbeam) can promote the occurrence of natural tree hollows in forests. Hornbeam has a specific trunk structure (e.g. spiral grain, thin bark, numerous indentations and ingrown bark) (Fig. 1). The aim of this study was to determine which species of trees are associated with natural tree hollows and with necroses (which promote the formation of natural tree hollows). Natural tree hollows and necroses were predicted to be associated with hornbeam more than with other tree species found in managed forests.

The study was done in the Niepołomice Forest $\left(50^{\circ} 02^{\prime} \mathrm{N}, 20^{\circ} 33^{\prime} \mathrm{E} ; 10596 \mathrm{ha} ; 200 \mathrm{~m}\right.$ a.s.l.), a lowland temperate forest in the western part of the Sandomierz Basin in southern Poland. One hundred square study plots $(10$ ha each, $316 \times 316 \mathrm{~m})$ were demarcated, with nine subplots $(20 \times 25 \mathrm{~m}$ rectangles $)$ distributed regularly (as a layout of $3 \times 3$ subplots) in each of the 100 plots. In each subplot, natural tree hollows and necroses were noted on the trunks of all trees thicker than $30 \mathrm{~cm} \mathrm{DBH}$, and their species was also recorded for each tree. The chi square test was used to investigate the relationship between the occurrence of tree-related microhabitats (natural tree hollows and necrosis) and the tree species. Each tree species was characterized by two parameters: the number of individuals with the presence of tree-related microhabitats and the number of individuals without this microhabitats.

A total of 7649 trees thicker than $30 \mathrm{~cm}$ on dbh were recorded on research plots, including 1836 oaks, 414 hornbeams, 403 lindens, 382 alders and 4614 pines. Natural hollows were found on 128 trees and necrosis on 726 trees. The chi square test showed that the presence of natural tree hollows $\left(\chi^{2}=71.34\right.$; $p<0.0001)$ and necrosis $\left(\chi^{2}=43.51 ; p<0.0001\right)$ in the managed stands of the Niepołomice Forest is strongly dependent on the tree species. Among all studied tree species, hornbeam it was the one with the 
most of natural tree hollows and necrosis (Fig. 2). It has been shown that natural tree hollows and necrosis occur most often on hornbeams thicker than $41 \mathrm{~cm}$ in DBH (Fig. 3).

The reason why natural tree hollows and necroses occur more often on hornbeam than on another tree species is probably related to the relatively thin bark, the ease of damage to bark, and the natural structure of the trunk (numerous indentations, cracks along hornbeam trunks and branches). Hornbeam was not promoted in Polish managed forests formerly, probably due to its tendency to have frequent and numerous wood defects (e.g. curvature, spiral grain, necroses). However, in recent years the share of hornbeam in Polish forests has been increasing. Since the 1990s there has been a slight return to promotion of hornbeam in Polish managed forests, perhaps due to an increasing demand for its firewood, of high calorific value. This may increase the number of microhabitats related to hornbeam, such as necroses and natural tree hollows.

The important role of hornbeam in the creation of necroses and natural tree hollows leads to the conclusion that the increase in the share of this tree species in managed forests should be maintained. Promotion of hornbeam as part of forest regeneration projects is not enough to increase the number of tree-related microhabitats associated with it. Hornbeams should be allowed to reach old age in managed forests. These trees, along with their tree-related microhabitats, can increase forest biodiversity and permit endangered species to survive.

Wptynęto: 24.01.2020 r.; przyjęto do druku: 03.03.2020 r. 